\section{INNOVATIVE POTENTIAL OF PERSONALITY: SYSTEMIC ANTHROPOLOGICAL CONTEXT}

Vitaly Y. Klochko,

Eduard V. Galazhinsky

Tomsk State University

Tomsk

Conceptual grounds of the system anthropological psychology, that allow to represent the innovative potential of a personality in the context of understanding the mechanisms of self-development of a person as an open self-organizing system, are discussed in the article.

Keywords: innovative potential of a personality, innovative behaviour, system anthropological psychology.

The concept of "innovative personality" was introduced by Everett Hagen (1963), who regarded it as a prerequisite for economic growth, development of entrepreneurship and capital accumulation. The assumption behind this is that there are different "personality syndromes", polarity of which represents the typical features characteristic of the traditional and modern societies. The first type of society has an authoritarian personality, the second one - a different in all the aspects - an innovative personality. With the reference to the theorists of post-industrial information society (Reich, 1992; Drucker, 1993; Castells, 2000), it can be stated that the vehicle of the modern economy are the people, and, first of all, those who have the potential to transform their opportunities into reality, especially in the way of searching, identifying and using information. New economy requires a new kind of worker; it puts to the forefront creative potential of a person, their professionalism and erudition, ability to "be redundant", to exceed the roles and functions, where they can be substituted and are just mortal bearers of "an immortal social beginning". The shift from technocratic to anthropocentric organization of labour and production is occurring.

In any case, modernity, viewed as an epoch of innovative social development, makes special demands of a person. To meet these require- ments it is necessary to have certain personality orientations, qualities and values, which could empower a person to participate effectively in innovative processes. The innovative behaviour has other than "a tensed need" source of activity in itself. Having recognized this other source of a person's activity, many theories of classical and non-classical orientation started their development.

There have been singled out quite a lot of different empirical indicators and personality traits, connected with the processes of origin of an incentive to the innovative behaviour. These criteria have been identified in the process of studying personalities of innovators - people who show inclination to entrepreneurship or have achieved much success in it. In other words, researcher's attention was focused on (and is still being focused on) the problem of personality causation of the motivational processes ensuring a personal involvement into an entrepreneurial activity. The major question asked was related to the definition of personality traits which must be characteristic of people who are able to fulfill an entrepreneurial function, taken into consideration that an entrepreneur is an innovator by nature, i.e. a person with a certain psychological profile.

It can be supposed that the set of all these indicators conditions the personality resource which defines an innovative potential of a person. However, several issues remain unresolved:

- all these indicators, being empirical, do not constitute a system: their inclusion in the innovative potential of a person is not theoretically grounded, they do "intersect", duplicating each other in a way, but there is a feeling though that they are not linear and represent details of a multi-level ensemble;

- even accepting the fact that these indicators characterize completely the innovative potential of a person, it still remains problematic how and why are potential abilities of a person actualized under one conditions, and are not under the other ones;

- classically and non-classically oriented psychological thought could not overcome the dichotomy of the internal and external factors causing the incentive to entrepreneurial activity "here and now"; overcoming this dichotomy is possible within the principle of system determinism (as one of the methodological means of the post non-classical science);

- the so-called "dialectical method" implies considering all the facts and processes "in the general interrelation, interdependence and devel- 
opment", that makes it possible to define three interrelated principles: system, determinism and developmental principles; namely these principles had been identified a while ago as priorities in psychology, but only now they are being connected not in a declarative way, not by means of "a methodological sticking together" in some kind of their abstract unity, but by means of identifying a self-developing system (a person).

"Tensed opportunity" is a source of the innovative behaviour. That is why it is necessary for its understanding to exceed the bounds of a search for the role of the psychic in the achievement of "sustainable condition" of a system.

Here the first place is not taken by the sustainability of a condition, but is taken by the "flow sustainability" (homeohresis), when the appearance of the new in a system (in the process of its self-development) is what ensures the sustainability of a system's existence in time and space.

The core of the problem of the innovative behaviour is that it can be and must be by its nature understood as a phenomenon of an overadaptive order, though motivation for "going beyond the borders" (conventional norms, traditions, orientations, stereotypes, situational requirements etc.) has not been explained yet. Significance of the problem is increased by the fact that it is not possible to solve the problem of the motivation for innovative behaviour by analyzing the motives due to which people try to explain the grounds of behaviour forms of going "beyond the borders" manifested by them.

It can be assumed that a special, characteristic only of a person, form of transition of an opportunity into reality manifests itself in the phenomena of an innovative behaviour. This means that the process of personal self-development has been actualized.

In the system anthropological psychology a vast body of theoretical, methodological and methodic knowledge has been obtained which can be viewed as a basis for the development of the theory of motivation for the innovative behaviour, based on the understanding the selfdevelopment mechanisms of a person as an open self-organizing system (Klochko, 2008a).

The system anthropological psychology is understood by us as a relatively recent scientific development. Its special feature is defined by the fact that its authors' objective, while developing the methodological basis of this approach, was to ensure that it follows the mainstream tendencies of the objective development of the psychological cognition.
It may seem that this task is redundant. Indeed, if we agree with L.S. Vygotsky that objective tendencies of the science development exist as intangible powers, "standing behind the back" of a researcher and overriding their "mind and will" (Vygotsky, 1982), then it does not make sense to spend time trying to become aware of them. After all, any researcher is in the environment where these powers are active no matter whether a researcher is aware of them or not. On the other hand, objectivation of the tendencies themselves allows researcher to penetrate deeply in the heart of the "paradigm shift", to become aware of their place in the mainstream science, that is to establish a connection with those ones who had been working in science before, and will be working after.

Our researches show that the tendencies of science development can be identified with the help of the historic system approach, viewing it as a particular case of the transspective analysis application for researching the regularities of the scientific cognition movement (Klochko, 2008b). The transspective analysis is not just an approach to studying a dynamic phenomenon, but it is also a principle of studying the phenomenon in the process of its emergence, i.e. in the process of continuous complexity growth of system organization, characteristic of complex integrities (open systems). A series of accomplished researches proved that science can be viewed as an open system which complexity growth is accompanied by the sequential growth of system characteristics of the professional psychological thinking. Axiomatics on which the system anthropopsychology is built upon have absorbed almost all the methodological basis of TPS (Klochko, 2005). Referring to the "history of the question" it should be noted that the major question was related to the nature of interaction as a phenomenon having a generative effect. Experimental researches (which were carried out at the beginning of 70's of the last century within the framework of the research program which later became what is known today as the meaning based theory of thinking developed by O.K. Tikhomirov) allowed to fix the moments of meaning emergence, what made it possible to maintain that meanings appeared on their own and not as a result of special ("meaning forming") activity of a person (Klochko, 2005). The meanings "formed themselves" by settling themselves down on objects and marking them as significant, necessary, adequate to a person's current condition. This "unexpected outcome" was attained through an attempt to confirm L.S. Vygotsky's hypothesis about the unity of affect and intellect, 
an attempt to experimentally "detect" this unity (Vygotsky, 1986). At that point we encountered self-organization as characteristic of persondimensional systems for the first time. This unity revealed itself in a special way. Affect (emotion) goes ahead of cognition (reflection), attitude goes ahead of reflection, paving the way for a voluntary activity, guiding logical procedures, reducing and structuring search zones for a solution of the task. Emotions pointed at meanings which turned out to be one of the characteristics of the elements comprising the logical structure of a situation. It became clear that meanings (as well as emotions which "read" them) guided those objects into the consciousness which were adequate to a person's current condition.

That was how the multidimensional psychological reality, "subjectively distorted" objective reality (L.S. Vygotsky), but allowing to act in a selective manner, had been revealing itself. To any change in a person's condition (initiation of searching activity, motivation, goals etc.) the situation answered by the dynamics of the value meaning system together with which the object based (formal logical) structure of the situation was rebuilt. Gradually it became clear that this was particularly what made the difference between a situation and other objective reality, i.e. it had the value-meaning laden dimension, being not only a part, an actual, dynamic and sustained sector of a person's life.

To make an interaction itself possible, such coherence of the opposing parties (systems) is necessary when each of the parties sees in another one "their own other", even though it has not yet become genuinely "their own", but having not had taken it for their own, i.e. having not included it in the system, the possibility of a system's sustainable existence is called into question. In essence it is about a law which ensures an order in the universe - the law of interaction restriction. Chaos exists only where there are no interactions at all or any interactions are allowed. Occurred in teraction by itself points at the coherence which has become the cause of interaction. Interaction itself manifests coherence to the same extent as coherence functions as the only and sufficient cause for an interaction. This is the mechanism of self-organization which is characteristic of the open systems. Where there is coherence, interaction happens in a self-arbitrary and will free manner, when we are talking about a person. Only open systems are capable of sustaining their intrinsic order through selecting exclusively from the environment what can sustain this order. Making themselves more complex in every act of interaction through including into themselves "their other", writing it into themselves and restructuring themselves, systems develop the level of their system organization and exist as long as they increase their complexity. That is why self-organization is a necessary requirement for self-development of the complex systems. This is the way the nature of their evolution is assumed, no matter whether it is a person, a scientific theory, a biogenetical system, or any other system which can be considered an open one. Axiomatics of the theory of self-organizing psychological systems was built upon these postulates. Through the prism of this theory became clear L.S. Vygotsky's thought that "psyche is the highest form of selection" (Vygotsky, 1982, p. 347) and S.L. Frank's words that "a person is a living center of the situational powers aimed at reality. This intrinsic, subjective attitude of a person to reality, this orientation of a human soul to the world, shaping the very essence of what we call our life... was left outside the scope of a usual, the so-called "empirical psychology" (Frank, 1995, p. 441).

It was shown that such noticeable tendencies as humanization, humanitarization, onthologization of psychological cognition actually represent various manifestations of general tendencies of science development in the field of its anthropologization. One can be sure that psychologists will try to elaborate all the potential sources which have at least an allusion to containing knowledge about the nature of a person as an integrated phenomenon. Initiation of different projects such as humanistic, existential, humanitarian, Christian psychologies proves that this process is already occurring in science. We maintain that scientific psychology, as it seems, is giving up the efforts to discover the function of psyche, making psyche itself the subject of research. Probably, gradually occurring understanding of illusionary attempts to guess the function of psyche, its mission and destination (psyche reflects, orientates, regulates, anticipates etc.) and on the basis of an empirically identified phenomenon build some integral (system defined) notion about it, is one of the causes of modern psychology crisis. Indeed, almost all of these guesses have acquired a status of explanatory principles a while ago.

In contrast to other variants of the anthropological psychology (or "psychological anthropology" - a notion which is often used as a synonym or analogue of the anthropological psychology) we use the notion "system anthropological psychology". It does not necessarily mean that other variants of the anthropological psychology are "not system defined" or "less system defined". We do not want to emphasize by this no- 
tion (system defined) the quality of a theory, but assert our understanding of the image of a person in psychology. A person gradually becomes the subject of the psychological science, but the outcomes of the transspective analysis assure us that the psychological (and not any other) study of a person starts in the case when the consciousness, psyche, the psychic in general begin to be understood through the mission they accomplish in the system of an integrated person, providing them with an opportunity to emerge (and remain) as an open self-organizing system with self-development being a regime of its existence. The system principle formulated in this form acquires a paradigm status. In the theory of the psychological systems known as TPS (abbreviation), development of which was started by one of the authors (V.Y. Klochko), a person is viewed as a complex dynamic spatial-time unity.

Anthropological move which objectifies the possibility of development of the psychological cognition "from a person to psyche" had been built into the TPS from the very beginning. This move was difficult to implement due to the following reasons. Firstly, this move contradicted the mainstream movement of psychological thought "from psyche to a person", accompanied by the attempts to understand the function of psyche, studying it and making different assumptions about the purpose of this most complicated device. The vast body of these assumptions has been gathered: psyche reflects, orientates, regulates, adapts etc. Some of those assumptions still remain not only authoritative, but also prioritized. The problem is that neither one of those assumptions, nor their sum do not bridge the gap in our knowledge about psyche. This gap is being inevitably and constantly reproduced because an intimate relation of psyche to higher order "integrity" with which it is hierarchically and subordinately connected is being continuously revealed in researches. Secondly, at that time a thought about the coming of post non-classical stage of science development, priority subject of which would have become self-developing person-dimensional systems, had not yet been articulated not only in psychology, but even in epistemology. That is why it was quite difficult to prove the very possibility of theoretically (in a system way) identifying the subject of a science. It was even more complicated to talk about that in the process of studying a system which though had been theoretically identified was a real system (a "living" and developing one) when a special role of psyche had been discovered which could not be even thought of in the process of its cognition as an established (empirically identified) subject of a science. That was why at the first stages of TPS development it did not make a lot of sense to put an emphasis on the anthropological character of a paradigm being followed.

System focus (a person as a self-organizing system) defines only one out of the possible ways of approaching a person as a subject of psychological (and not any other) cognition, drafting at the same time the borders of subject and problem fields which predetermine the number and quality of scientific tasks, solution of which is acceptable in the framework of the given methodology.

There exists an opportunity to take into consideration objective tendencies of the emergence of the psychological cognition and understand that such frequently singled out tendencies as humanization, humanitarization, onthologization of psychology, which are viewed as a rule as separate and linear, are actually only different forms, different manifestations of the tendency of anthropologization of the psychological cognition. This tendency reflects the essence of the paradigm shift occurring in science. Apart from that, the level of psychologists' system thinking has changed: it has become much easier for them to understand a person as a self-organizing system. Post non-classical science refers to this kind of systems which means that quite persistently discussed in scientific literature issue of the "architecture" of science, based on the ideas of post non-classical rationality, will lead in the end to an integrated person, to a system defined person as a subject of the science.

Within the framework of this approach the psychic represented itself in its spatial continuousness - as something that ensures a longterm range of a whole system, allowing it to select form the environment what is adequate to its actual needs (e.g. makes sense) and appropriate (e.g. has the status of value since self-development is the shift from an opportunity into reality, providing for the sustainable existence of a system). In fact, this determined the transition of the theory to the field of system anthropology. It turned out that this transition does not exclude methodological principles of psychology which have naturally been developed, but integrates them in the frames of a new and more complex principle. For example, system, developmental and determinism principles lose their autonomy when a self-organizing system becomes the subject of the science. The principle of system determinism which allows to objectify those effects of self-organization, which are viewed as new psychological formations, determining the choice of particu- 
lar directions for self-development that is made by a person, acquires a critical importance. "Self-actualization of a person" is only a form in which self-development of a person - a major means of their existence as an open self organizing system - is represented (Galazhinsky, 2002) We are convinced that anthropological psychology is quite a broad subject and problem field of science, boundaries of which are only outlined, but the transspective of the psychological cognition is directed towards these fields in particular.

Diversity of scientific theories is an integral part of scientific progress. At the same time this diversity itself reflects an evolutionary direction of the scientific progress. This fact is embraced by the notion of "transspective": science is not developed from the inside, but being an open system, it interacts actively with its environment and enriches itself through actively drawing from it missing models of thinking, manners of argumentation, examples of overcoming the dichotomies, images of a person which exist in the area of philosophical, religious, cosmological, esoterical and any other knowledge.

Knowledge about the way of forming "the multidimensional life space" of a person, about the sequence of acquisition of this space of the new dimensions, about rising up of a person's consciousness to the new level as a consequence of that, has been developed (Klochko, 2005). Thus, a person themselves reaches a new level of sovereignty increasing the level of openness and demanding a new educational environment which would have made this process continuous and coordinated with themselves. Theory and practice of education has to include a special task of coordinating these demands with educational actions and influences in a list of top priorities. Educational projects have to meet these expectations, i.e. they have to be coordinated with the regularities of the emergence of "the personal in a person", which can not be ignored or evaded even by means of the latest educational (pedagogical) "technologies". Only providing this coordination makes it possible to ensure the regime of self-development of a person under conditions of education as a social institute. A child of a person is a special phenomenon, essence of which is an opportunity (to become a person), concentrated within its small body that exists under conditions of "tensed expectation" for such external conditions interaction with which will allow this opportunity to turn into reality. Equifinality is a dynamic feature of an educational system, organizing the transfer of children coming from a common start and different initial conditions to one and the same final condition - having become a person, being a person. Regularities lie not in the diversity of transitional ways, which is clear by itself, but in the availability of those stages and phases which a child would have to go through before becoming an accomplished (an integrated) person - a sovereign personality capable of being involved into an innovative activity aimed at the outer world as well as at itself (self-building, self-development etc.).

Psychological study of a person begins in the case when the consciousness, psyche, the psychic in general become to be understood through the mission that they accomplish in the system of an integrated person, ensuring their possibility to become (and remain) an open selforganizing system, existence regime of which is self-development.

One of the important criteria of the effectiveness of modern system of education is providing conditions for developing competitiveness of a person, development of an innovative sphere, development of labour resources able to reproduce and develop material and intellectual potential of a country, ensuring social and professional mobility, establishing human resource elite of the society. The task of developing fundamentally new conditions and new environment for the intellectually gifted young people in the regions with high innovative potential is becoming a top priority. The problem though is that neither educational theory nor practice has not yet directly encountered the problem of designing and implementing such an educational environment which would have been directly aimed at training an "innovative personality". Such a personality whose characteristic features would be advanced motivation for an innovative activity, high potential of self-actualization, readiness to change established behaviour patterns, tolerance to ambiguity and other features which can be summarized under the notion of "innovative potential of a personality".

Within the framework of this approach the innovative potential of a personality is understood as a personality resource which under certain conditions can manifest itself as a fundamental ground for initiation of the innovative behaviour (Galazhinsky, Klochko, Krasnoryadzeva, 2009). One such condition is modality of emotional and orientation complex, which allows a person to become involved into the regime of self-development (to transfer opportunities into reality) when an opportunity to shift to this regime occurs in the environment. Thus, the innovative potential includes: 
1. Personality characteristics such as tolerance to ambiguity, capability of reasonable risk-taking, responsibility, need for self-actualization, achievement motivation, reflexivity, creativity (features of intellect, intellectual initiative).

2. Competences, first of all, such as project competence, communicative competence, information competence.

3. Vitality (peculiarities of value-meaning organization of a life space, viability, sovereignty, efficiency, mobilizing potential, level of self-regulation, orientation at a particular quality of life).

In this respect, longitudinal research of initiation (production) of thinking in connection with the problem of initiation of an innovative activity, acquires a special meaning (Klochko, 2008a). Special significance is attributed to questions about the origin and mechanism of regulating the "free action", "over normative activity", "over normative behaviour", "above situational activity" etc. There is a global problem behind these questions of psychological mechanisms of self-development and crossing the borders of any "norms" or "situational requirements", the problem of development of person's own norms ("norm creation"), the problem of "psychological heterostasis", the mechanisms which are not understood from the point of view of their functioning in a particular situation.

The process of thinking as a basis for creative activity is always crossing the borders of a norm, standard, tradition, that is withdrawal from some system (functional, normative, institutional). If not justification, but at least an explanation of creative, innovative intention of a subject is needed for further returning back into to the system, without which "creation" it becomes meaningless.

In the notion of "initiation" one can see two different roots: "creation" (appearance, emergence) and "initiative" (goal-forming undertaking free of the intension on the final result). The two aspects merge in the notion "initiation" - both creative and initiative, process-activity related and personal. They can not be separated, as it is not possible to tear away the process of a "new norm" creation from a situation of activity in which it has been formed (and which has been regulated by "an old norm"), and from a person, who has discovered in the process of this activity an opportunity for self-development, having realized by that inherent in them level of the "innovation initiative".

Solution of the problem of initiation of the innovative activity is possible in the case when not separate psychic qualities, features and conditions, but complexes, integrative unities, in which there exist outer situational and situational formations, ensuring sustainability, dynamics of an activity and being an intrinsic condition for an activity transformation, are made the subject of the research. In the context of the notion "self-developing psychological system" the true meaning of the interrelation between emotions and orientations is revealed. They manifested themselves as an indivisible complex inside of which it is not possible to single out an emotion or an orientation, the complex which can not be reduced to their simple, arithmetic sum, but represented itself as a system, integrative feature, characterizing the integrated system. It was defined by the notion "emor" (by the initial letters of the words "emotion" and "orientation"). The regulatory character of emotional-orientation complexes reveals itself in the integration of an evaluation of a situation and readiness to act under its conditions in a particular way, providing for sustainability and dynamics of an innovative activity at the stage of its origin.

Methodological and theoretical research, carried out by the authors of the article, allowed to formulate a notion of motivation for the innovative activity as an integrative characteristic of a person, conditioning initiation (generation) of the innovative activity and including two constituents: an innovative potential of a personality and motivational readiness for an innovative activity. At the same time, motivational readiness for an innovation activity is generally defined as an ability of a person to transform conventional forms of behaviour under conditions of diverse socialeconomic environment. It is psychologically manifested in the initiation of the innovative activity under such conditions when the environment provides opportunities adequate to the innovative potential of a person, to a personality resource which is a major basis for the appearance of an incentive to the innovative activity (Galazhinsky, 2008).

These definitions provide a clear understanding that motivation for the innovative activity is a system characteristic. That is why it is not possible to analyze one element of this system - motivational readiness for the innovative activity without its relation to another core element - the innovative potential.

Within the framework of these conceptual developments the innovative behaviour is understood as a behaviour which is manifested through going beyond the boundaries of the existing orientation and behaviour stereotypes and is not initiated by the system of periodically reproduced needs, but emerges in an innovative way at those spots of a person's life 
space where at least three factors merge. These factors are: 1) opportunities of a person represented by their personality, spiritual, creative, intellectual etc. potential; 2) environment adequate to those opportunities, that is an environment which is structured by the value-meaning markers and where self-actualization is possible; 3 ) readiness of a person to realize their opportunities "here and now" (Galazhinsky, Klochko, Krasnoryadzeva, 2009).

The special and only characteristic of a person form of transition of an opportunity into reality manifests itself in the phenomena of the innovative behaviour. Thinking is included into this process and fulfills the most significant function: it meditates the processes of rebuilding the way of life and the image of the world by reaching a time-based consensus among them, which is necessary for ensuring that a person maintains their integrity as a sustainable self-developing system.

The vector of emerging of "the personal in a person" is drawn along the line of an increasing openness, building-up opportunities and their turning into reality, search for environments which would meet growing demands, "falling away in the flow". Complexity and diversity of the modern educational environment does not meet the opportunities of a person. Only a few people in modern educational practice turn out to be involved in the flow of self-movement (an initiative act, self-development, self-actualization). In this connection, it makes it critical to create educational environments aimed at the so-called "schools of the flow", that is "schools" of positively understood regularities of a person's self-movement in the space of a joint-distributed activity. On the one hand, opportunities of a person are building up, and on the other hand, the complexity of system's organization is regularly increasing in the process of transformation of opportunities into reality. Pedagogues, having realized this, turn into anthropotechnicians, and psychologists, researching the process of developing of a person and anticipating its next stage, become co-designers of the new, more and more complex educational environments.

The personal aspect of a specialists training for an innovation sector of economics acquires today a special significance, as professional activity at the time of "global innovations" is based on widening the borders of a person being aware of their opportunities, independent activity in defining alternative and efficient for a particular situation professional environments and ways of self-actualization, reaching an agreement with themselves in the context of social goals. Addressing this context of professional training is considered to be an adequate answer of the higher education to the serious challenge facing the modern education. This challenge is the admittance of the fact that the human resource is becoming to be the most important and meaningful resource of country's social and economic development. In this respect, modern education is not simply regarded as the sphere of academic knowledge reproduction, transferring and learning the "past" experience, but it assumes the status of producing, "constituting" human resource and capital. Such understanding of the core of innovations in higher education is needed which allows to consider them in the context of the anthropological grounds of project and innovative activities in education.

The major research priorities within the given field are focused on the development and implementation of such psychological-educational programs and technologies which:

- determine "personal presence" of a person in their education and provide opportunities for their involvement in and influence on their education;

- ensure formation and formulation of their own educational orientations, educational initiatives and their implementation in educational, professional and research activities;

- create conditions for an educational choice and definition of a person's own way, an individual educational trajectory;

- provide training for an innovative activity, for an activity under conditions of uncertainty and tough competitiveness of market relations;

- develop competences of effective group interaction, effective communication and joint activities, necessary for life in an open environment.

We have developed an understanding of psychological-educational following-up of the process of involving the young into the innovative activity as a special culture of individuality's socialization, which is being formed and developed following the principle of coherence between the opportunities of a person (including ability to learn) and such educational environment which can meet these opportunities. In this case an educational environment becomes a developmental one in which opportunities turn into reality (emergence). Such educational environment coordinated with the opportunities of a person turns into an open educational space where a person (as an open system) discovers resources for self-development and whose opportunities become potencies acquiring the power for self-fulfillment. 


\section{References}

Castells, M. (2000). The Institutions of the New Economy. In "Delivering the Virtual Promise" Conference. Queen Elizabeth Hall. London. 19 June 2000. From www. brunel.ac.uk/research/virtsoc/text/events/castells.htm

Drucker, P.F. (1993). Post-Capitalist Society. New York: Harper Collins.

Frank, S.L. (1995). Predmet znaniya. Dusha cheloveka [The Subject of Knowledge. Soul of a Person]. Sankt-Peterburg: Nauka.

Galazhinsky, E.V. (2002). Determinatsiya i napravlennost' samorealizatsii lichnosti [Determination and Directivity of a Person's Self-actualization]. Tomsk: Izdatelstvo TGU.

Galazhinsky, E.V. (2008). Perspektivnye napravleniya psihologicheskogo obespecheniya obrazovatel'nyh proektov $\mathrm{v}$ regione s vysokim innovatsionnym potentsialom [Prospective Directions of Psychological Maintenance of Educational Projects in the Region with High Innovation Potential]. Psihologiya obrazovaniya, 8. Moskva. P. 4-10.

Galazhinsky, E.V., Klochko, V.Y., Krasnoryadzeva, O.M. (eds.) (2009). Psihologiya innovatsionnoy deyatel'nosti: tezaurus (slovar', ohvatyvayuschiy spetsifiku professional'noy leksiki) [Psychology of an Innovational Activity: Thesaurus (Dictionary of Professional Vocabulary)]. Tomsk: Tomskiy gosudarstvennyj universitet.

Klochko, V.Y. (2005). Samoorganizatsiya v psihologicheskih sistemah: problemy stanovleniya mental'nogo prostranstva lichnosti (vvedenie $v$ transspektivnyj analiz) [Self-organization in Psychological Systems: Problems of Emergence of the Mental Space of a Person (Introduction into the Transspective Analysis)]. Tomsk: Tomskiy gosudarstvennyj universitet.

Klochko, V.Y. (2008a). Sistemnaya antropologicheskaya psihologiya i obrazovatel'naya praktika [System Anthropological Psychology and Educational Practice]. Psihologiya obrazovaniya, 8. Moskva. P. 9-2.

Klochko, V.Y. (2008b). Modern Psychology: Systems Meaning of a Paradigm Shift. In Y. Zinchenko, V. Petrenko (eds.) (2008). Psychology in Russia: State of the Art. Moscow: Department of Psychology MSU \& IG-SOCIN. P. 25-40.

Reich, R.B. (1992). The Work of Nations: Preparing Ourselves for 21st Century Capitalism. New York: Vintage, Boors.

Vygotsky, L.S. (1982). Istoricheskiy smysl psihologicheskogo krizisa [Historical Meaning of the Psychological Crisis]. In Sobranie sochinenij v 6 tomakh. Tom 1. Moskva: Pedagogika.

Vygotsky, L.S. (1986). Konkretnaya psihologiya cheloveka [Concrete psychology of a person]. Vestnik Moskovskodo universiteta. Serija 14. Psihologiya, 1. P. 1-60. 